\title{
Influence of Bursectomy on Operative Morbidity and Mortality After Radical Gastrectomy for Gastric Cancer: Results of a Randomized Controlled Trial
}

\author{
Yukinori Kurokawa • Yuichiro Doki
}

Published online: 2 November 2011

(C) Société Internationale de Chirurgie 2011

Kayaalp et al. [1] ask about the effects of combined resection of other organs on the complication rates and the operating time in the patient series we reported [2]. After dividing the patients in the study into two subgroups according to the presence of combined resection, the number of patients suffering from any complication was same in each group (three in each group among patients without a combined resection; 12 in each group among patients with a combined resection). Although the operating time was not similar between the bursectomy and the non-bursectomy groups, the differences did not show statistical significance in either subgroup $(P=0.101$ among patients without a combined resection; $P=0.149$ among patients with a combined resection), probably because of the small sample size. Likewise, there were no significant interactions between bursectomy and combined resection on these end points.
Regarding the effects of bursectomy on such specific complications as delayed gastric emptying, bowel obstruction, or afferent loop syndrome, we think there is a possibility of postoperative adhesions to the mesocolon and pancreas after bursectomy, as stated in the Discussion.

\section{References}

1. Kayaalp C, Piskin T, Olmez A (2011) Complications of bursectomy after radical gastrectomy for gastric cancer. World J Surg. doi:10.1007/s00268-011-1218-0

2. Imamura H, Kurokawa Y, Kawada $J$ et al (2011) Influence of bursectomy on operative morbidity and mortality after radical gastrectomy for gastric cancer: results of a randomized controlled trial. World J Surg 35:625-630. doi:10.1007/s00268-010-0914-5
Y. Kurokawa $(\bowtie) \cdot$ Y. Doki

Department of Gastroenterological Surgery,

Osaka University Graduate School of Medicine, Osaka, Japan

e-mail: ykurokawa@gesurg.med.osaka-u.ac.jp 